\title{
Pensando os limites: arte contemporânea e a Mímesis
}

Eduardo da Silva de Freitas ${ }^{a, b}$ (D)

\begin{abstract}
Resenha de:
COSTA LIMA, L. Limite. Rio de Janeiro; Belo Horizonte: Editora da PUC-Rio ; Relicário Edições, 2019.
\end{abstract}

A uma obra já vasta e imponente, acrescentou Luiz Costa Lima, em 2019, mais um título com a publicação de Limite, pela editora da PUC-Rio e pela Relicário Edições. Professor emérito da PUC-Rio, Costa Lima tem mantido por décadas a fio intensa produção intelectual no campo da teoria e da crítica literárias, do qual desenvolve uma reflexão que tem se espraiado para a área das Humanidades. Dos estudiosos de literatura no país, é ele um dos poucos cuja repercussão no estrangeiro não é devida ao interesse que desperte em algum brazilianist, senão que à relevância de sua contribuição para o campo em que atua, o dos Estudos Literários. Essa contribuição se concentra sobretudo numa proposta de ressignificação da mímesis, cujo corolário é uma reflexão que se estende sobre a tríade sujeito-representaçãoverdade e redimensiona o estatuto epistêmico da ficção, das artes e, em especial, da literatura.

a Universidade Federal do Rio de Janeiro, Faculdade de Letras, Rio de Janeiro, RJ, Brasil.

b Universidade do Estado do Rio de Janeiro, Programa de Pós-Graduação em Letras, Rio de Janeiro, RJ, Brasil. E-mail: eduardosfreitas@letras.ufrj.br 
No âmbito de uma atividade intelectual cuja inflexão mais significativa, segundo o próprio autor (COSTA LIMA, 2010, p. 126), remonta a quatro décadas, Limite pode ser visto como uma obra de sedimentação de elementos teóricos centrais das pesquisas que o autor levou a cabo sobre a mimesis. $\mathrm{O}$ fato, no entanto, é que, sendo a sistematização que ora se apresenta de grande importância, não é a única contribuição do livro. $\mathrm{Na}$ busca de compreender o fenômeno da mímesis - eixo por meio do qual dialoga com a filosofia, a história, a psicanálise, além, obviamente, da literatura e das artes plásticas -, Luiz Costa Lima discute temas importantes da arte, relativos tanto à sua produção quanto à sua circulação, com ênfase na contemporaneidade.

Nesse sentido, se o autor justifica o título, Limite, como o reconhecimento de ter atingido o termo de sua capacidade para encontrar novos desdobramentos para suas teses (COSTA LIMA, 2019, p. 26), ele pode ser adequado ainda para caracterizar a própria atividade intelectual de Costa Lima, em contraposição à ampla tendência do cenário intelectual tanto no Brasil quanto no exterior. Ora, enquanto paira sobre os críticos e artistas contemporâneos a ideia de um apagamento de fronteiras entre gêneros textuais, Costa Lima adota posicionamento diverso, buscando justamente definir os lugares e os papéis a serem ocupados e desempenhados em cada caso, por cada tipo de discurso. Sua reflexão sobre a mímesis, que recupera os insights aristotélicos sobre o tema com vistas a superar certos entraves do pensamento do Estagirita, se traduz numa tentativa não só de delimitar as fronteiras entre as formações discursivas, como também de circunscrever a experiência estética, sobretudo a incidente na literatura ficcional, em confronto com a experiência pragmática.

É verdade que a discussão sobre a experiência estética e a pragmática tornou-se o mote de muitos teóricos, mas ao passo que, por exemplo, entre os desconstrutivistas, se apela principalmente para a dimensão irracional do ser humano e se denuncia o racionalismo, Costa Lima busca preservar o legado iluminista, moderando-o e dando-lhe um encaminhamento segundo o qual a razão, não desprezada, não se projete para além do campo de sua competência ou de suas capacidades, a fim de que se abra espaço para o reconhecimento da importância de outras dimensões 
existenciais e de outras formas discursivas, especialmente as da literatura. Os resultados mais recentes dessa investida têm consistido, nas palavras de Aline Magalhães Pinto (2019, apud COSTA LIMA, 2019, p. 14), "em construir uma reflexão teórica atenta à plasticidade dos processos geradores envolvidos nas formações discursivas, em especial a ficcional, conectada a uma capacidade ou potência humana que plasma o desejo em imagem."

Mímesis e imagem são, de fato, questões centrais do livro ora tratado. Este se divide em quatro capítulos, precedidos de uma breve apresentação. Nela, o autor trata do Mímesis e negatividade, do português Fernando Gil. A apresentação e os quatro capítulos, por sua vez, são enfeixados por um prefácio de Aline Magalhães Pinto e um artigo de Carlos Rincón, este sobre a recepção de Auerbach no México e no Brasil. Na "Apresentação", Costa Lima apenas registra suas discordâncias quanto a algumas posições de Fernando Gil em seu referido livro. Os reparos dirigem-se à compreensão da relação entre sujeito e representação pelo escritor português, à concessão que este faz ao elemento de sentido em detrimento do sensível, e ao fato de sua argumentação não visar propriamente à mímesis (COSTA LIMA, 2019, p. 23-25).

Venha-se ao capítulo 1, “Uma visão parcial e interessada da arte". Aqui, o autor apresenta o esboço de uma história da mímesis. Feito em cerca de noventa páginas, ele só pode ser parcial, como reconhece o autor (COSTA LIMA, 2019, p. 29), indicando com isso que sua função é principalmente contribuir para sua proposta de ressignificação da mímesis. Talvez se possa resumir assim a tese que orienta o esboço: depois de um momento inaugural na Grécia - quando seus sentidos ainda oscilavam entre práticas artísticas diversas, como a música, a dança, o teatro e a poesia -, a mímesis ficou confundida com a ideia de "imitação" até o século XVIII, quando tal ligação é contestada, ao mesmo tempo em que a mímesis é descartada em favor da valorização da subjetividade; desde então, o campo da arte tem experimentado uma dispersão de critérios que, por desconsiderar a relação entre sujeito e realidade, têm se mostrado incapazes de consolidar um espaço para a arte.

Quanto ao contexto grego, sem se limitar a recriminar Platão e elogiar Aristóteles, Costa Lima comenta as ideias de Stephen Halliwell e Paul Woodruf sobre os dois filósofos. 
O teórico brasileiro entende que a tese de Halliwell consistente em alertar que a mímesis platônica não se confunde automaticamente com "imitação" e que seu emprego se projetava para além do campo da arte - subestima na obra platônica a relação entre mímesis e "imitação" esquece-se de que Platão punha a arte em posição subalterna. Além disso, ele critica a leitura de Woodruf, segundo a qual a mímesis em Aristóteles nada mais é do que um engano. Para Costa Lima, além de insistir na posição ancilar da arte, a tese de Woodruf desconsideraria a complexidade do pensamento aristotélico sobre a mímesis.

Da ideia de imitação, cujos modos de atualização se ligaram, ora à reprodução da natureza, ora à ilustração dos dogmas e da moral religiosa, a mímesis só conseguiu se afastar no século XVIII, com Baumgartem e Kant. Os escritos de Baumgartem sobre a arte, que cunhou o termo "estética" como hoje o entendemos, abrem espaço para a valorização e compreensão do sensível. A ideia de "heterocósmico" formulada por Baumgarten registra o reconhecimento do ficcional, uma vez que o termo designa uma existência que se dá no intervalo entre o mundo real e o impossível. Os esforços de Baumgarten, contudo, esbarrariam no seu preconceito de subordinar o sensível ao lógico, indo na contramão de sua valorização da experiência sensível. As Críticas de Kant, por sua vez, dando larga atenção à ética e à estética, voltavam o pensamento filosófico para o âmbito da existência em que o entendimento não comanda a experiência.

Costa Lima nota que, embora fosse possível, a partir de Kant e Baumgarten, encontrar caminhos que superassem a identificação da mímesis com a "imitação", o conceito acabou descartado no século XVIII. O período inaugurou a dispersão de critérios avaliativos da arte e afastou o recurso a critérios objetivos na apreciação das obras, bloqueando a teorização e a instrumentação do conceito de mímesis - ressalva feita à crítica marxista de cunho hegeliano, que, porém, mantém a indesejada relação. Tomando os escritos de Paul Valéry, Gerald Bruns e George Steiner, como exemplos dos caminhos desde então palmilhados por artistas, críticos e teóricos, Costa Lima defende que eles têm conduzido a uma hipertrofia da subjetividade, traduzida na afirmação e na promoção da arte como experiência subjetiva em detrimento da razão, numa 
postura que ergue tanto uma barreira para reflexão da relação entre real e obra de arte quanto permeabiliza as fronteiras discursivas entre o fictício e a realidade.

O percurso encerra-se pela análise da situação de crise vivida na arte contemporânea diante da expansão do consumo, dos mass media e das manifestações correlatas da pop-art, promotora de questionamentos à ideia de arte, de objeto artístico e de crítica de arte. A carência de parâmetros objetivos para avaliação da obra de arte teria levado à desestabilização do campo, com desalojamento da crítica especializada em favor dos interesses do mercado. Assim, a multiplicação das exposições não corresponderia a um aumento de interesse pela arte, senão que atestaria a "marginalização de alguma concepção de arte [,] de sua subordinação e dependência da função mercadológica." (COSTA LIMA, 2019, p. 107).

O capítulo 2, "Mímesis e representação", retoma mais frontalmente questões abordadas em Mímesis: desafio ao pensamento, de 2000. Costa Lima volta-se para o conceito de representação por meio dos projetos filosóficos de Descartes e Kant e depois analisa a incidência da mímesis no discurso histórico e no literário. Sua ideia de representação-efeito seria uma proposta de afastamento do sujeito cartesiano, concebido como ser uno, e uma abertura para a compreensão e aceitação do tipo de representação desprezada por Descartes: aquela em que sujeito e objeto não estão polarizados. Costa Lima insiste que não se trata de privilegiar o que chama de representaçãoefeito, mas de reconhecer os limites e inadequações da representação tradicional, empregada no campo das ciências matemáticas e naturais, para os campos das Humanidades. Daí sua aproximação da filosofia kantiana, em cujas Críticas vê a demonstração da "plasticidade inacreditável" (2019, p. 133) do sujeito para atualizar os diferentes tipos de experiência de que o filósofo trata.

Costa Lima observa que Kant não só aprofundava o gesto cartesiano de fundamentação da possibilidade de conhecimento no próprio sujeito como também se ocupava com as faculdades humanas desprezadas pelo filósofo francês. Para ele, a distinção estabelecida por Kant entre os juízos determinantes e reflexivos, e, nestes, a identificação de um juízo propriamente estético - "o da finalidade sem fim" (2019, p. 150) -, criavam condições para a quebra do elo entre mímesis 
e "imitação", mas não foi isso que se deu, mesmo no ambiente cultural alemão, dentro do qual a língua distingue entre representação (Vorstellung) e apresentação (Darstellung). Então, vista como duplicação, a "representação [foi] marginalizada, em prol da expressão da interioridade do homem" (2019, p. 165), que se furta à "imitação".

Registrado o alijamento da mímesis do campo da literatura, o capítulo seguinte, “Ostracismo e mímesis", trata da ociosidade do conceito no âmbito da filosofia, encerrando-se por uma apreciação do pensamento de Didi-Hubermann sobre a imagem. Ao criticar a filosofia husserliana e as tendências filosóficas oriundas de sua fenomenologia, Costa Lima busca afastar-se do essencialismo, cujos pressupostos contestavam o plano teórico em que se sustentavam "quer o pensamento filosófico, quer as ciências humanas" (2019, p. 173). O teórico acusa também o desprezo pela mímesis, nos filósofos alinhados à fenomenologia, como Sartre, Adorno, Habermas, Foucault, Deleuze e Merleau-Ponty. A crítica correlata ao desprezo, a de se confundir mímesis e "imitação", fica reservada a René Girard, Walter Benjamin e Phillipe Lacoue-Labarthe, que, para Costa Lima, se servem, respectivamente de argumentações reducionistas, místicas e estratosféricas, para estabelecerem a malfadada associação.

Para discutir as ideias de Didi-Huberman sobre a imagem, o teórico estabelece uma diferença quanto a seu emprego conforme o campo do saber em que é aproveitada. Enquanto nas ciências da natureza se prevê uma univocidade entre conceito e imagem, na crítica da arte essa condição dá lugar a uma relação mais oblíqua, por meio da qual o conceito é cercado por "um halo metafórico" (COSTA LIMA, 2019, p. 217), uma vez que lida com uma dimensão existencial não passível de ser matematizável. Ademais, dizendo-se precavido quanto à "abordagem muitas vezes sofística" (COSTA LIMA, 2019, p. 219) de Didi-Huberman, Costa Lima identifica no pensamento do autor francês uma tendência normativa quanto à apreciação da arte, inclinada à valorização "tão só das posições divergentes do status quo." (COSTA LIMA, 2019, p. 231).

Costa Lima entende que a reflexão de Didi-Huberman sobre a imagem, enquanto projetada sobre o pano de fundo da crise na arte contemporânea vista como dilaceração do figurativo, propõe como alternativa à situação crítica "o destaque 
da indeterminação do signo" (2019, p. 235), em detrimento do mimético. A interpretação empolgada de Didi-Huberman da minimal art como esvaziamento do antropomórfico, em favor das formas e da geometria, é questionada por Costa Lima. De seu ponto de vista, por um lado, o indeterminado "confunde-se com o ornamental" (2019, p. 239), e, por outro lado, o minimalismo tanto deixa espaço à arbitrariedade do intérprete quanto não alcança impulsionar a imaginação para além da vivência cotidiana, esvaziando o objeto daquilo que o tornaria arte (COSTA LIMA, 2019, p. 245-246).

No capítulo final, o autor sintetiza suas ideias sobre a mímesis. Sua caracterização parte da defesa de que na Poética, Aristóteles intui uma situação específica no amplo campo de atuação da mímesis. Para Costa Lima, ao apontar que sentimos prazer quando "observamos situações dolorosas, em suas imagens mais depuradas" (ARISTÓTELES, Poética, 1448b, 1015 apud COSTA LIMA, 2019, p. 250), o filósofo grego depara-se com uma situação em que a mímesis ultrapassa o mero instinto. Associando a intuição de Aristóteles às teorias freudianas, Costa Lima pensa a mímesis como fruto de uma impulsão (Trieb) - não do instinto - "da necessidade de uma 'identidade subjetiva'", que, em sua origem "implica uma Entstellung (truncamento), em que o 'sujeito do desejo' se inclui." (COSTA LIMA, 2019, p. 259).

Nesse momento inicial da impulsão, chamado de mímesis zero, o referido sujeito não teria identidade própria e apenas assumiria uma na medida em que ocupasse "o lugar de um outro (que não é outro sujeito, senão um outro constituído imaginariamente), desenhando-se uma alienação originária (que não se confunde com a alienação) e um engodo (tampouco confundido com o que se entende por engodo)" (COSTA LIMA, 2019, p. 259). Assim, "em sua modalidade artística, ou seja, ficcional, a mímesis provoca[ria] um 'distanciamento do eu'." (COSTA LIMA, 2019, p. 260). Acrescenta o autor que, no passo inicial, a ficção não é ainda sinônimo de obra de arte ou de suspensão necessária do "primado da verdade". Antes, se trata de algo que "se se cumprir em uma disposição textualizável", não poderá ser "tomado como restituição de algo de fato sucedido." (COSTA LIMA, 2019, p. 261).

Dessa impulsão inicial, surge o phantasma - a ideação - formado do "embate entre a imaginação e o 'princípio de 
realidade', que provoca a Entstellung" (COSTA LIMA, 2019, p. 262). Por um lado, considerada fruto de uma impulsão, a mímesis não franquearia o acesso do consciente aos procedimentos mentais que a desencadeiam; por outro lado, redirecionado pela Entstellung (truncamento) que conduz a impulsão ao mundo exterior ao sujeito, o inconsciente toma forma pelo "conjunto de valores sociais que se interpõem entre a expressão do eu e sua possibilidade de manifestação." (COSTA LIMA, 2019, p. 263). Desse modo, ligando sujeito e realidade, Costa Lima defende que na arte a mímesis não é simples cópia, já que sujeito e objeto não estão polarizados, nem é pura expressão subjetiva, já que, para se manifestar como arte, é preciso que se canalizem minimamente os elementos da realidade.

Por fim, Costa Lima retoma a discussão da necessidade de se repensar uma teoria do conhecimento que incorpore as experiências que não se deixam fixar conceitualmente, segundo os parâmetros típicos das ciências. Voltando a questões tratadas especialmente em Os eixos da linguagem, destaca que, nas experiências não matematizáveis, existe um hiato entre o nome e o nomeado, que é trabalhado diferentemente segundo o compromisso que a formação discursiva tenha com a verdade (COSTA LIMA, 2019, p. 278). Em lugar de se descartar ou diminuir a importância dos produtos de suas atividades, a proposta seria entender como o campo das Humanidades operacionaliza aquilo que ultrapassa a dimensão do estritamente científico.

Feita a apresentação, talvez seja oportuno fazer um breve comentário. Em Limite, Costa Lima insiste em sua ressignificação da mímesis contra o pano de fundo da situação de crise vivida pela arte contemporânea. É em contraposição às linhas de força atuais do campo que o autor testa sua teoria. Neste sentido, vale notar que especialmente depois da Segunda Guerra Mundial, a intensificada dispersão do campo das Humanidades (entre as quais está a arte) tem provocado sua reordenação (na visão dos otimistas) ou esfacelamento (na dos pessimistas). Integrante deste último grupo, Costa Lima argumenta que, no campo da arte, justamente algumas das reiteradas propostas contemporâneas de aproximação entre vida e arte têm significado a contração da experiência estética, num mundo onde "não há fronteiras que a banalidade não possa invadir." (COSTA LIMA, 2019, p. 114). A propalada "morte da 
arte" - amiúde celebrada como libertação dos paradigmas que entravavam a comunhão do mundo por autor, obra e leitor - é denunciada por Costa Lima, se não como armadilha, ao menos como posição fragilizadora da arte diante do mercadológico (COSTA LIMA, 2019, p. 115). Nas palavras do autor:

A morte da arte, em suma, é contemporânea não de obras que, com qualidade efetiva, apontam para sua crise, mas para um tempo em que não há lugar senão para o mercadológico. Tudo mais é supérfluo ou conduzido à conversão da realidade em fictício. (COSTA LIMA, 2019, p. 115).

O último período da citação remete à questão das formações discursivas, com o que Costa Lima contraria a homogeneização de ficção e realidade. Pensando a condição dos discursos, o teórico brasileiro procura entender como funciona a relação entre sujeito e representação segundo suas relações com o primado da verdade. Ao que parece, sua teoria propõe que quanto maior for o peso desta, maior é (ou deveria ser) o esforço do sujeito em se distanciar de seu objeto ou, ao menos, de objetivar seus juízos, no caso da impossibilidade de demonstração absoluta. Entre outras possibilidades, isso se prestaria não só a reconhecer as especificidades dos discursos, mas também a evitar que eles sejam instrumentalizados de forma inadequada, seja por ingenuidade, seja por perversidade. Se o que fica dito está certo, é daí que parece decorrer sua desconfiança quanto à tendência contemporânea de misturar ficção e realidade. Para ele, a prática da arte contemporânea de transformar a preocupação platônica de indistinção entre o fictício e o real em sua pretensão e meta, em lugar de instaurar o revide da arte contra a razão, tem promovido efetivamente a perda de valor da arte e, com isso, a delegação da fala apreciadora do objeto artístico a instâncias não especializadas.

Embora não seja mencionado por Costa Lima, um pequeno trecho de Jacques Rancière pode servir para ilustrar as imbricações contemporâneas entre realidade e ficção: "A política e a arte, tanto quanto os saberes, constroem 'ficções', isto é, rearranjos materiais dos signos e das imagens, das relações entre o que se vê e o que se diz, entre o que se faz e o que se pode fazer." (RANCIÈRE, 2005, p. 59). Deixandose de lado o que pode significar o emprego das aspas por Rancière na palavra "ficção", apenas se tome a passagem para 
a tentativa de captar a posição de Costa Lima. Ela apresenta ter um encaminhamento geral e outro mais específico. Parece que o teórico não negaria que a ficção desempenha papel crucial em muitas práticas discursivas fora da arte, mas talvez ressaltasse que os "rearranjos materiais dos signos e das imagens" são dependentes das finalidades que incidem sobre os discursos e que tais finalidades têm em vista sua inscrição no mundo. Nesse sentido, a investida na homogeneização entre as instâncias do fictício e do real, embora dê a entender um congraçamento geral, pode ter um efeito perverso, como sugerem os comentários de Costa Lima (2019, p. 99 e 270) sobre o recente impedimento da presidente em 2016.

Por outro lado, no campo específico da arte, a reflexão de Costa Lima parte da visão de que o apagamento das fronteiras tem contribuído para consolidar duas situações correlatas. Uma delas é o estabelecimento do "império dos curadores" (COSTA LIMA, 2019, p. 170), que consiste em se desprezar o conhecimento dos especialistas (tanto dos artistas, quanto dos críticos) em favor da mercantilização da arte. A outra é que a não afirmação de um espaço próprio tem mantido a arte como "um exercício vital para participantes ou experts, efetivos ou simulados, que, em princípio, precisam ter uma atividade profissional outra, que lhes garanta a sobrevivência." (COSTA LIMA, 2019, p. 115).

Enquanto tentativa de superação desses condicionamentos históricos em que a arte tem se encontrado, a especulação de Costa Lima sobre a mímesis não se confunde com o abstracionismo. Ao contrário, trata-se de uma empreitada intelectual que busca, entre outras questões, estabelecer os limites da arte, não tanto para territorializar o campo quanto para que ele não se torne vítima de uma manipulação que subverte sua estrutura, bem como para que se lhe reconheça espaço devido no conjunto das atividades humanas. Tal intento, aliás, é manifesto já na própria linguagem e no encaminhamento argumentativo de Costa Lima, que, fugindo aos cintilantes paradoxos e às formulações vistosas que pervadem muitos textos de críticos e teóricos contemporâneos da arte, instaura, nas palavras de Aline Magalhães Pinto, um estilo que "por não admitir superficialidades, não concede aos leitores a não ser o mais absoluto rigor e a maior das seriedades." (2019, p. 13). 


\section{REFERÊNCIAS}

ARISTÓTELES. Poética. Tradução de Paulo Pinheiro. São Paulo: Editora 34, 2015

BASTOS, D. (org.). Luiz Costa Lima: uma obra em questão. Rio de Janeiro: Garamond, 2010.

COSTA LIMA, L. Limite. Rio de Janeiro; Belo Horizonte: Editora da PUC-Rio ; Relicário Edições, 2019.

PINTO, Aline Magalhães. Prefácio. In: COSTA LIMA, Luiz. Limite. Rio de Janeiro; Belo Horizonte: Editora da PUC-Rio; Relicário Edições, 2019.

RANCIÈRE, J. A Partilha do Sensível. São Paulo: Editora 34, 2005.

COSTA LIMA, L. Mímesis e modernidade. In: BASTOS, D. (org.). Luiz Costa Lima: uma obra em questão. Rio de Janeiro: Garamond, 2010. p. 125-157.

Thinking the Limits: Contemporary Art and the Mimesis

Review of the book: COSTA LIMA, L. Limite. Rio de Janeiro; Belo Horizonte: Editora da PUC-RIO; Relicário Edições, 2019.

Eduardo de Freitas é Professor Adjunto do Departamento de Letras Clássicas da Faculdade de Letras da UFRJ. Doutorou-se, no ano de 2013, em Literatura Comparada no Programa de Pós-Graduação em Letras da UERJ. Desde 2019, atua como Professor nesse mesmo Programa, na Linha de Pesquisa "Literatura: teoria, crítica e história", da Área de Estudos Literários. 